\title{
The Oxford Cold Driven Shock Tube (CDST) for Fuel Spray and Chemical Kinetics Research
}

\author{
Joseph Camm, Martin Davy, Xiaohang Fang, Luke Doherty, Matthew McGilvray, and Felix Foerster \\ University of Oxford
}

\begin{abstract}
A new reflected shock tube facility, the Cold Driven Shock Tube (CDST), has been designed, built and commissioned at the University of Oxford for investigating IC engine fuel spray physics and chemistry. Fuel spray and chemical kinetics research requires its test gas to be at engine representative pressures and temperatures. A reflected shock tube generates these extreme conditions in the test gas for short durations (order milliseconds) by transiently compressing it through a reflected shock process. The CDST has been designed for a nominal test condition of $60 \mathrm{bar}, 900 \mathrm{~K}$ slug of air ( $300 \mathrm{~mm}$ long) for a steady test duration of $3 \mathrm{~ms}$. The facility is capable of studying reacting mixtures at higher pressures (up to 150 bar) than other current facilities, whilst still having comparable size $(100 \mathrm{~mm}$ diameter) and optical access to interrogate a fuel spray with high speed imaging and laser diagnostics. Future data gathered will support fundamental research for IC engine and fuel technologies leading to even higher thermal efficiency along with a reduction in emissions, and provide high quality, repeatable validation data for advanced model development. This paper describes the scope of the facility's capabilities, aspects of its design, details of the instrumentation, and the axially mounted single-hole diesel injector.
\end{abstract}

\section{Introduction}

Further development of IC engine technologies to meet demanding efficiency and emissions targets requires both continuing improvement in the predictive capability of engine simulation and the study of new concepts that allow step changes in capability $[1,2]$. This is also needed to optimize IC engine operation for new roles in hybrid powertrain architecture [1]. To provide insights into the behaviour of combustion strategies or fuels and develop numerical models, there is a continued need for high quality experimental data at engine representative conditions. Future alternative combustion strategies, such as Gasoline Compression Ignition and Partially Premixed Compression Ignition, will utilize in-cylinder conditions that differ from those found in conventional compression ignition engines, meaning that data for auto-ignition and fuel spray behaviour are not widely available for these strategies. New and alternative fuels, including many variants of biodiesel from a variety of sources, have been proposed as a means to reduce the greenhouse gas impact of hydrocarbon combustion [3]. Characterization of the auto-ignition, liquid injection and atomization quality of these fuels is required before they can be adopted for general use. Of particular interest is the measurement of parameters including: the fuel liquid and vapour penetration from the injector nozzle, estimations of the local droplet size distribution, fuel mass and temperature distribution in the spray,

Page 1 of 9 ignition delay, the distance from the nozzle of the lifted flame (lift-off length), flame extinction behaviour, spatial and temporal flame soot levels.

Investigation of compression ignition conditions requires the direct matching of engine pressure and temperature conditions to ensure replication of the physical and, particularly, the chemical processes. This is of increased importance when investigating the behaviour of sprays in fuel/air mixtures that approach or exceed the supercritical state during injection or the mixing process [5], due to the variation in mixing behaviour from classical evaporation through to diffusive mixing. Thus, any facility built to investigate these will need to generate a range of appropriate pressures, temperatures and chemical compositions.

Researchers around the world have produced a range of solutions for performing these experiments. Constant volume electrically heated or pre-burn chambers (e.g. Sandia, USA; IFP, France; ETH,

Switzerland) are typically capable of reaching over 100 bar and $1200 \mathrm{~K}$ using pre-combustion; however, this requires the experiment to be carried out with combustion products as part of the ambient gas. There is typically an overshoot in temperature and pressure, and the experiment is triggered once the pressure has fallen to a predetermined level. Residual motion from the initial combustion event can contribute to interference in the background, which may be visible on, for example, schlieren images [6]. With electrical heating alone, the range of temperatures achievable is lower due to heat losses to the ambient.

High pressure and temperature continuous flow chambers have been employed, for example at CMT, Spain and RWTH Aachen, Germany. These are capable of up to $1000 \mathrm{~K}$ and 150 bar. These require a continuous flux from a heated, high pressure reservoir, and much of the vessel and pipework therefore experiences an elevated temperature during operation.

Another method of generating engine relevant conditions, with optical access, is the rapid compression machines (RCM) (e.g. NUI Galway, Ireland; University of Brighton, UK). These can closely replicate engine geometries since they are often produced using hardware from a single-cylinder engine. However, gas motion can be introduced by the piston and the compression time takes on the order of $10 \mathrm{~ms}$, which affects pre-mixed auto-ignition experiments by introducing a temperature history to the mixture. 
Table 1: Overview of existing facilities suitable for fuel spray and chemical kinetics research, showing typical achievable conditions where available

\begin{tabular}{|c|c|c|c|c|c|}
\hline Facility & Mode & Reference & \begin{tabular}{|l} 
Typical \\
peak \\
pressure \\
(bar)
\end{tabular} & \begin{tabular}{|l|} 
Typical \\
peak \\
temperature \\
$(\mathrm{K})$
\end{tabular} & Size \\
\hline Sandia & $\begin{array}{l}\text { Pre-burn } \\
\text { constant } \\
\text { volume }\end{array}$ & {$[5,9]$} & 350 & 1400 & $\begin{array}{l}108 \mathrm{~mm} \\
\text { cube }\end{array}$ \\
\hline IFP & $\begin{array}{l}\text { Pre-burn } \\
\text { constant } \\
\text { volume }\end{array}$ & {$[9,10]$} & 120 & 1500 & $\begin{array}{l}125 \mathrm{~mm} \\
\text { cube }\end{array}$ \\
\hline ETH & $\begin{array}{l}\text { Pre-burn } \\
\text { constant } \\
\text { volume }\end{array}$ & {$[11]$} & 100 & 1000 & \\
\hline CMT & $\begin{array}{l}\text { Constant } \\
\text { flow } \\
\text { vessel }\end{array}$ & {$[12]$} & 140 & 1000 & $\begin{array}{l}120 \mathrm{~mm} \\
\text { diameter }\end{array}$ \\
\hline Aachen & $\begin{array}{l}\text { Constant } \\
\text { flow } \\
\text { vessel }\end{array}$ & {$[13]$} & 50 & 800 & $\begin{array}{l}100 \mathrm{~mm} \\
\text { diameter }\end{array}$ \\
\hline $\begin{array}{l}\text { NUI } \\
\text { Galway } \\
\text { RCM }\end{array}$ & & {$[14]$} & 40 & 1050 & \\
\hline $\begin{array}{l}\text { Brighton } \\
\text { RCM }\end{array}$ & & {$[15]$} & 140 & 720 & $\begin{array}{l}50 \mathrm{~mm} \\
\text { diameter }\end{array}$ \\
\hline $\begin{array}{l}\text { ITLR } \\
\text { Shock } \\
\text { Tube }\end{array}$ & $\begin{array}{l}\text { Double } \\
\text { diaphragm }\end{array}$ & {$[8]$} & 50 & 2000 & $\begin{array}{l}50 \mathrm{~mm} \\
\text { square }\end{array}$ \\
\hline $\begin{array}{l}\text { UBC } \\
\text { Shock } \\
\text { Tube }\end{array}$ & $\begin{array}{l}\text { Double } \\
\text { diaphragm }\end{array}$ & {$[7,16]$} & 30 & 1400 & $\begin{array}{l}59 \mathrm{~mm} \\
\text { diameter }\end{array}$ \\
\hline $\begin{array}{l}\text { NUI } \\
\text { Galway } \\
\text { High } \\
\text { Pressure } \\
\text { Shock } \\
\text { Tube }\end{array}$ & Heated & {$[14,17]$} & 70 & 1700 & $\begin{array}{l}63 \mathrm{~mm} \\
\text { diameter }\end{array}$ \\
\hline $\begin{array}{l}\text { Stanford } \\
\text { Aerosol } \\
\text { Shock } \\
\text { Tube }\end{array}$ & Heated & {$[18]$} & 7 & 1400 & $\begin{array}{l}100 \mathrm{~mm} \\
\text { square }\end{array}$ \\
\hline $\begin{array}{l}\text { RPI } \\
\text { Shock } \\
\text { Tube }\end{array}$ & Heated & {$[19,20]$} & 58 & 1400 & $\begin{array}{l}57 \mathrm{~mm} \\
\text { diameter }\end{array}$ \\
\hline $\begin{array}{l}\text { Oxford } \\
\text { CDST }\end{array}$ & $\begin{array}{l}\text { Double } \\
\text { diaphragm }\end{array}$ & & 150 & 1500 & $\begin{array}{l}100 \mathrm{~mm} \\
\text { diameter }\end{array}$ \\
\hline
\end{tabular}

Page 2 of 9
Reflected shock tubes have been previously employed to study nonreacting liquid fuel spray (ITLR, University of Stuttgart, Germany), gaseous fuel injection and ignition (University of British Columbia (UBC), Canada) and more typically fuel/oxidant mixture autoignition (e.g. NUI Galway, Ireland; Stanford University, USA). In the reflected shock region, the test gas is brought to zero velocity. Previous reflected shock tube installations have been shown to provide repeatable experimental conditions in the reflected shock region $[7,8]$. Since the duration of the shock heating processes is of the order of milliseconds, the increase in wall temperature in the test section is projected to be only around $5 \mathrm{~K}$. This provides a different thermal boundary condition than some of the previously described facility types. In addition, if a cold driver is used, as with the CDST, the metal temperatures throughout will be kept close to ambient, meaning they suffer no reduction in strength. This reduces the amount of material required to withstand the facility gas pressures.

At Oxford, it was decided to build a reflected shock tube facility, which became the CDST. The relatively low cost and simple experimental procedure, combined with the ability to generate higher temperature and pressure conditions than those available at other types of facility, made this an attractive choice. The CDST uses cold, compressed air to generate experimental conditions across most operating conditions. This is in comparison to the use of either heated gas (for example at CMT or RWTH Aachen), helium/argon mixtures (for example ITLR), or flammable mixtures (for example Sandia or IFP). The combination of pressure and temperature conditions that can be achieved are above those typically available at other reflected shock facilities at this size. In addition, auto-ignition studies of premixed mixtures are made simpler by the near instantaneous heating and compression of the test gases in a reflected shock tube. The CDST internal diameter was chosen to be $100 \mathrm{~mm}$ to allow investigation of a single-hole fuel spray without interference from wall effects. This is a larger size than many other reflected shock tube facilities. Shown in Table 1 are the achievable experimental conditions and vessel size for a range of existing facilities, for comparison with the CDST. The work described in this paper outlines the theory and design of the CDST reflected shock tube facility, and describes some of the details of the facility, including the optical test section that will be utilized for studying axially aligned fuel sprays. Finally, some preliminary results are presented, showing the test section pressure trace and some sample fuel spray images.

\section{Shock Tube Operation}

A reflected shock tube allows a high pressure gas (driver gas), in the driver section, to transiently shock heat an initially lower pressure gas (driven gas) to a high temperature and pressure. The two gases are initially separated by a diaphragm. With reference to Figure 1, the operation of a reflected shock tube can be explained as follows. State (1) is the initial state of the driven gas, also known as the test gas. This gas mixture will be the mixture observed in the experiment. State (4) is the initial state of the driver gas. After the diaphragm is ruptured, the driver gas begins to flow into the shock tube; this gas is state (3). The driver begins to empty via an unsteady expansion wave that proceeds from the diaphragm towards the end wall of the driver. The driver gas flowing into the shock tube is proceeded by a normal shock wave, which compresses the test gas to state (2). This shock is known as the incident shock, and the test gas behind the shock begins to move towards the end wall. Once the incident shock reaches the end wall, it is reflected, because the test gas cannot continue to flow past the solid boundary. The reflected shock returns towards the diaphragm and the test gas behind it is brought to zero velocity, and further compressed; this gas is at state (5). The experiment is then 
carried out in gas state (5), either by injecting fuel into this region or by observing the auto-ignition of shock heated air/fuel mixture in this region.

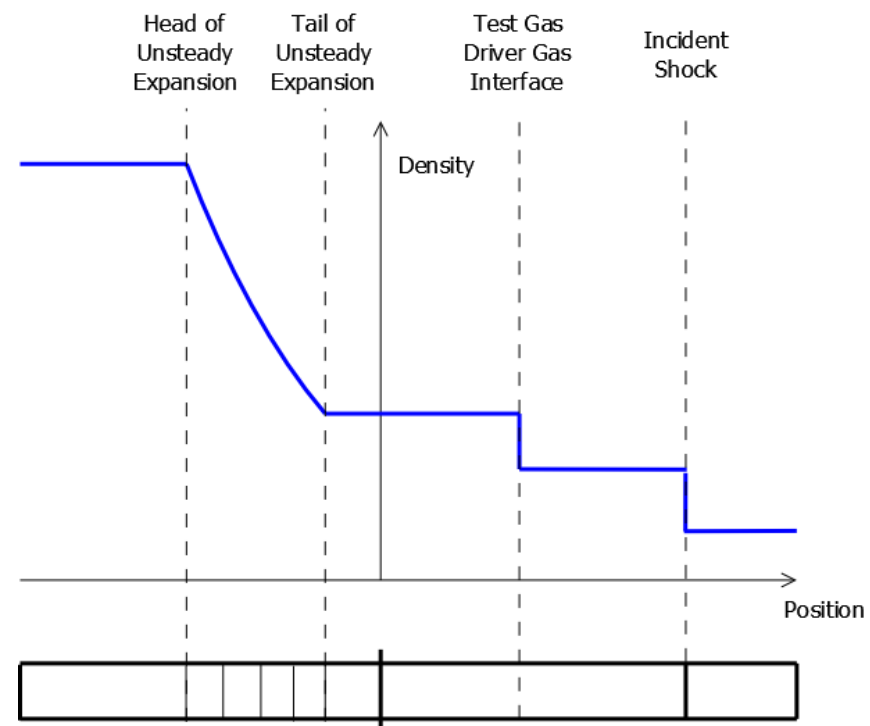

DRIVER TUBE DIAPHRAGM SHOCK TUBE

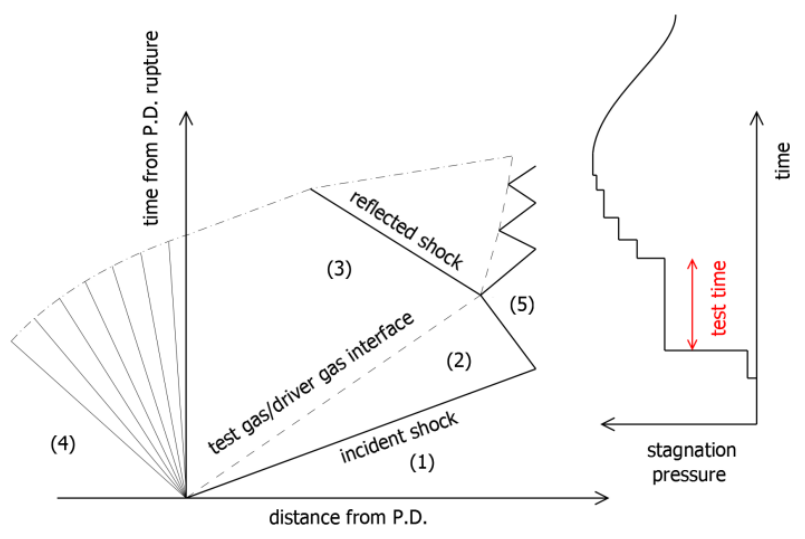

Figure 1: Top: Density distribution in different regions of a shock tube after diaphragm bursting. Bottom: An $x$ - $t$ schematic showing the behaviour in different regions in the shock tube, after diaphragm bursting, showing the variation of pressure with time at the reflected shock end. P.D. stands for primary diaphragm. The regions (1) to (5) are explained in the text
The reflected shock later reaches the interface between test gas and driver gas. Unless the sound speeds of the gas in (5) and (3) are equal, there will be reflection of either a shock wave or expansion wave back towards the shock tube end wall. In the case shown in Figure 1, there is a shock reflection back towards the end wall. This further alters the conditions at the end wall, where the experiment will be taking place, and effectively ends the experiment. The test time is shown as the time during which the pressure is held constant, with the gas being quiescent. A tailoring process can be applied to set the interface to a zero velocity condition when processed by the reflected shock, extending the test time. Typically, this is undertaken through careful choice of the driver sound speed and species. If applying a cold driver and the driver gas is the same as the test gas, tailoring is not possible.

\section{CDST Design}

A 3D CAD visualization of the CDST facility is shown in Figure 2, with the main features labelled. The shock tube is actually split across two rooms, with a purpose built laser diagnostics room surrounding the optical test section. Photographs of both inside and outside of this room are shown in Figure 3.

There are a variety of choices for the shock tube driver, which is the means of generating the shock wave that heats and compresses the test gas of interest to the desired condition. For the highest performance conditions (high total temperatures and stagnation pressures typically associated with hypersonic wind tunnels), the driver uses a piston or contained detonation to compress and heat the driver gas. Simpler methods include filling the driver reservoir with pressurized gas, which can be either cold (at ambient temperature) or heated by various means, for example resistive heating, arc heating or pre-burn heating (deflagration). It was determined that the nominal conditions could be reached using a cold driver. This further simplifies, and reduces the cost of, the operation of the facility, which requires only a supply of compressed gas to establish the shock tube driver conditions. A double diaphragm arrangement was designed to improve the control over the facility and allow decoupling of the driver fill pressure from the initiation of the experiment.

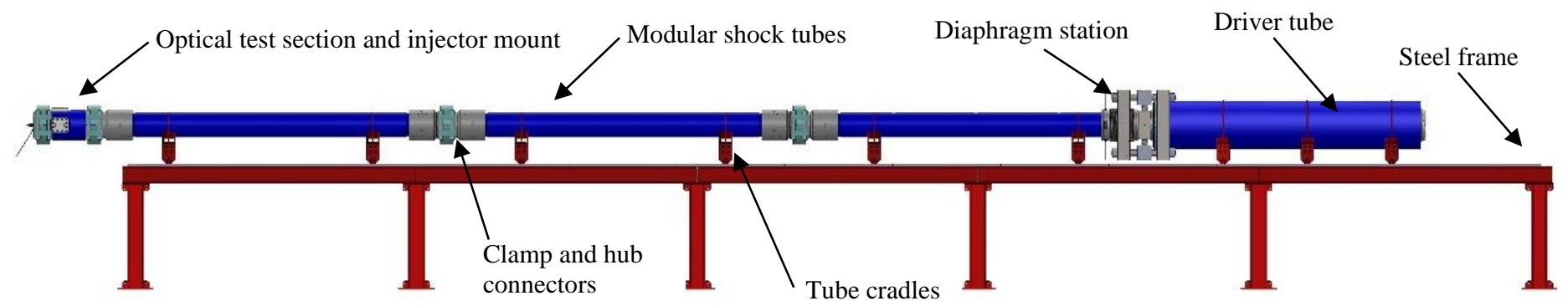

Figure 2: Side view of CAD model of CDST, showing the tunnel sitting on its cradles resting on a supporting steel frame. The optical test section at the left hand side overhangs an optical table (not shown) 

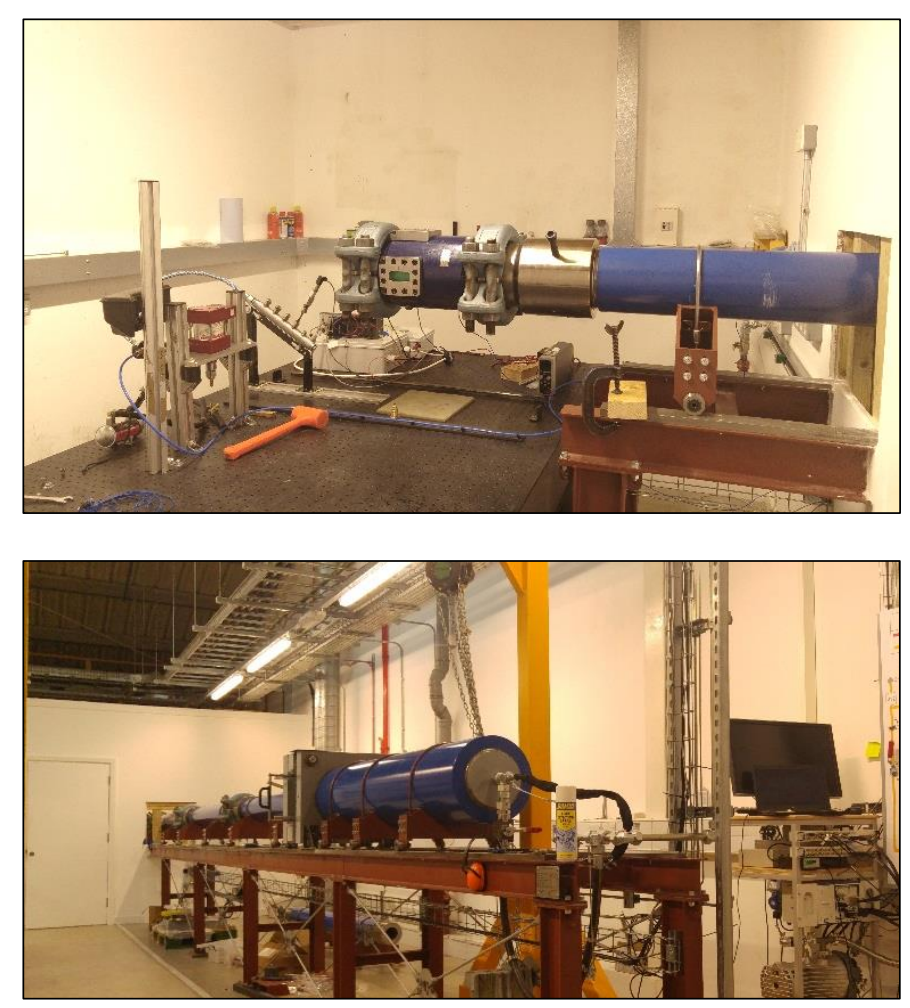

Figure 3: Top: Inside of the laser diagnostics room, showing the CDST test section, fuel delivery systems and optical table. Bottom: The remainder of the CDST facility showing the driver tube, diaphragm station and driven tubes

\section{Facility Design}

In this section, the design concepts and calculations that led to creation of this facility are outlined. The CDST was designed for the investigation of fuel spray and combustion at a range of conditions, including a nominal condition based around the Engine Combustion Network (ECN) Spray A experimental conditions of $900 \mathrm{~K}$ and around 60 bar, as first standardized by Pickett et al. [9], and a 'High' condition at further elevated temperature and pressure. The tube bore was set to $100 \mathrm{~mm}$, which would allow a single-hole, axially aligned fuel spray to be examined on the tube centreline in nominally quiescent conditions remote from the more complex multidimensional flow at the tube walls. This sizing was informed by the typical dimensions of a combusting diesel spray at the conditions of interest. The relevant dimensions are presented in Table 2 for the low temperature combustion condition of ECN Spray A.

Table 2: Typical Spray Dimensions for Spray A [21], for 60 bar and $900 \mathrm{k}$ case

\begin{tabular}{|l|l|}
\hline Steady state liquid length (non-reacting) & $10 \mathrm{~mm}$ \\
\hline Lift-off length (reacting) & $16 \mathrm{~mm}$ \\
\hline Vapour penetration at $1.5 \mathrm{~ms}$ ASOI & $60 \mathrm{~mm}$ \\
\hline Radial spread (observed from movies) & $25 \mathrm{~mm}$ \\
\hline
\end{tabular}

With the internal diameter fixed by consideration of the type of spray experiments planned, the design of the facility to meet the required experimental conditions and test duration was performed. For the ECN Spray A standard condition, the injection duration is $1.5 \mathrm{~ms}$. However, at this condition a target test time of $3 \mathrm{~ms}$ was chosen so that the full combustion event could be investigated, including endof-injection transient events. The design of the shock tube configuration was undertaken using a numerical tool called L1d [22, 23], which has also been utilized in the design of other facilities [8, 24]. L1d is a 1-D Lagrangian gas dynamics code, maintained by the University of Queensland. For the CDST, it has been used to predict the pressure and temperature history throughout the shock tube, for given initial gas pressures, temperatures and compositions. This allowed the selection of the required gas pressures to achieve the desired experimental conditions, and set the design pressure for the facility, which subsequently informed the mechanical design.

To achieve the desired experimental conditions, two configurations for the shock tube were conceived. An area change driver has been designed to produce the nominal conditions using air as the driver gas. This driver has a bore of $250 \mathrm{~mm}$ and wall thickness of $60 \mathrm{~mm}$, and the resulting reduction of flow area accelerates the flow into the shock tube, creating a stronger shock than would otherwise result from that combination of driver and driven gases and fill pressures. This allows the Spray A conditions to be reached for a $3 \mathrm{~ms}$ test duration utilizing a cold, air driver, reducing operational costs. The second configuration utilizes a constant area driver (bore $100 \mathrm{~mm}$, wall thickness $45 \mathrm{~mm}$ ), which is designed to be filled with a mixture of helium and argon gases. This allows the possibility of achieving tailored conditions, which will result in the test conditions being sustained for a longer duration. However, provision of suitable amounts of helium and argon gas increases the operating costs of the facility in this mode. The differences between the tailored and nontailored condition, resulting from the use of the constant area and area change drivers respectively, are depicted in Figure 4. In general, a longer facility will result in a longer test duration at given test conditions. The facility length was set to $10.9 \mathrm{~m}$ in area change mode and $11.25 \mathrm{~m}$ in constant area mode, as a compromise between space constraints and extending the test duration as much as possible.

A summary of the achievable conditions that were calculated using L1d are shown in Table 3. From these calculations a facility design pressure of 150 bar was selected for the mechanical design of the tubes and other components. A modular design was decided upon for the CDST, where the tubes of $100 \mathrm{~mm}$ diameter were manufactured in $2.5 \mathrm{~m}$ lengths and are connected together as required by the configuration. In the area change driver mode, designed to be operated with an air driver, the large diameter, single section, driver tube is $2 \mathrm{~m}$ long and sits upstream of the diaphragm station with three small diameter (100 $\mathrm{mm}$ bore) shock tubes downstream. In the constant area driver mode, there are two $100 \mathrm{~mm}$ diameter tubes upstream of the diaphragm station, and two downstream. The $100 \mathrm{~mm}$ diameter tubes are connected together by a clamp and hub arrangement, utilizing technology often employed in oil and gas pipelines, to provide a pressure sealed joint yet allow removal and reconfiguration for future tests. The shock tubes, driver tube and test section were all manufactured from AISI $4145 \mathrm{H}$ steel, with the bore honed on each component to a surface finish of N7. The hubs are nickel-plated A350 steel and the clamp sets are AISI 4140 steel. The ring that forms the seal at each tube joint is made from the precipitate hardened stainless steel, 17-4 PH. 

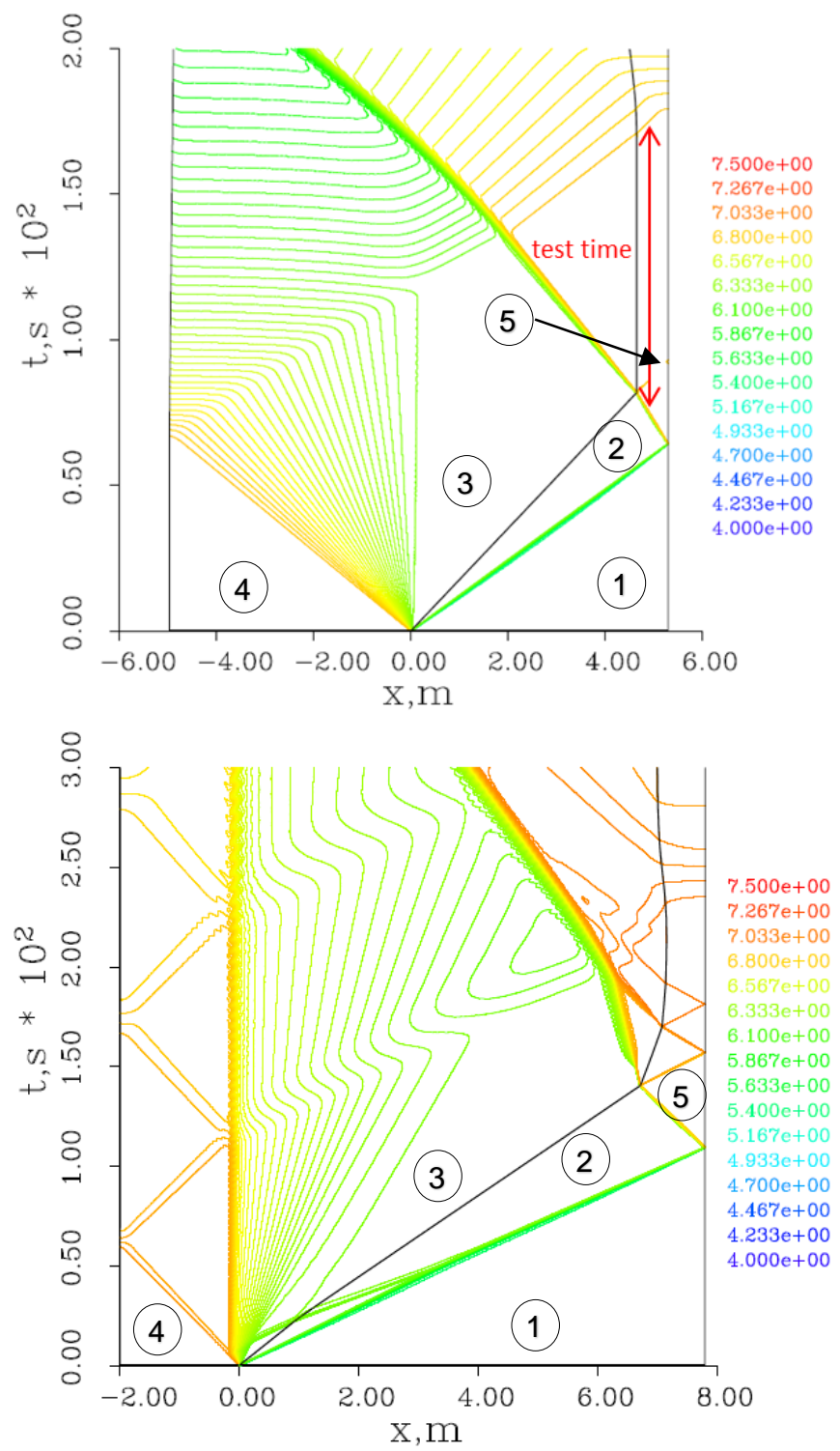

Figure 4: Top: Pressure contour map on a $x$ - $t$ diagram for the tailored conditions available by using the constant area driver with a suitable Helium/Argon mixture. Bottom: Pressure contour map on a $x-t$ diagram for the non-tailored conditions available by using the area change driver with air as the driver gas. The contours are on a logarithmic scale. The regions are: (1) - test gas fill, (2) - shocked test gas, (3) - expanded driver gas, (4) - driver gas fill, (5) - reflected shock condition

\section{Double Diaphragm Station}

The diaphragm station contains diaphragms that separate the high pressure driver gas from the low pressure driven gas. The CDST is able to operate a double diaphragm system to allow more controllable and repeatable diaphragm bursting events; this has been successfully employed at the ITLR shock tube (University of Stuttgart) and UBC shock tube $[7,8]$. With a single diaphragm system, the driver pressure must be increased until failure of the diaphragm plate occurs, which will be subject to variation due to factors including material properties, machining tolerance and variation in the manual clamping of the diaphragms in the diaphragm station. Thus, the driver pressure $\left(p_{4}\right)$ at diaphragm bursting cannot be tightly controlled. This pressure influences the temperature and pressure in the reflected shock region, where the experiment will be performed. Using a single diaphragm system also does not allow for a controlled triggering of the start of the experiment. The double diaphragm arrangement decouples $p_{4}$ from the burst pressure by venting the section between the two diaphrams as detailed below. This offers control over experimental conditions that is not matched with a single diaphragm configuration.

Table 3: Summary of the reflected shock test conditions attainable in the reflected shock region, as calculated in L1d simulations

\begin{tabular}{|l|l|l|l|}
\hline & Low & Nominal & High \\
\hline Pressure $\left(\boldsymbol{p}_{\mathbf{5}}\right.$, bar $)$ & 50 & 70 & 120 \\
\hline Temperature $\left(\boldsymbol{T}_{\mathbf{5}}, \mathbf{K}\right)$ & 500 & 900 & 1500 \\
\hline $\begin{array}{l}\text { Test duration - air } \\
\text { operation (ms) }\end{array}$ & 5 & 3 & N/A \\
\hline $\begin{array}{l}\text { Test duration - He/Ar } \\
\text { operation }(\mathbf{m s})\end{array}$ & 14 & 10 & 8 \\
\hline
\end{tabular}

The diaphragm station arrangement can be seen in Figure 5. A central diaphragm block, with internal bore $100 \mathrm{~mm}$ to match the downstream tubes, houses a diaphragm on each end. The diaphragms are typically made of aluminium or mild steel, depending on the required driver and shock tube pressure, and can be scored to facilitate a more reliable bursting manner. The diaphragm block is filled with a pressure intermediate to the driver fill pressure $\left(p_{4}\right)$ and the initial shock tube pressure $\left(p_{1}\right)$. The diaphragms are selected so that they will burst when subject to the full differential pressure $p_{4}-$ $p_{1}$, but will not burst when subject to the smaller differential pressure between the intermediate pressure and either $p_{4}$ or $p_{1}$. By rapid evacuation of the diaphragm block volume plus the volume of associated pipework (which is deliberately minimized) the bursting of the diaphragm (and initiation of the shock) is controlled only by the stable fill pressures of the shock tube and driver sections. This allows the test conditions to be set in a more controllable manner, and the experiment to be initiated by the operator, or aborted if necessary.

The diaphragms are sealed using ' $\mathrm{O}$ ' rings and compression is provided via a large threaded capstan nut arrangement on the downstream tube. This allows the entire downstream tube to be screwed into the downstream diaphragm flange, until a tight seal is generated on both sides of both diaphragms. Careful alignment of the downstream and driver tubes, the diaphragm flanges and diaphragm station rods, as well as the threaded nut and sleeve arrangement, was required to allow smooth movement and correct operation of the diaphragm station.

\section{Page 5 of 9}




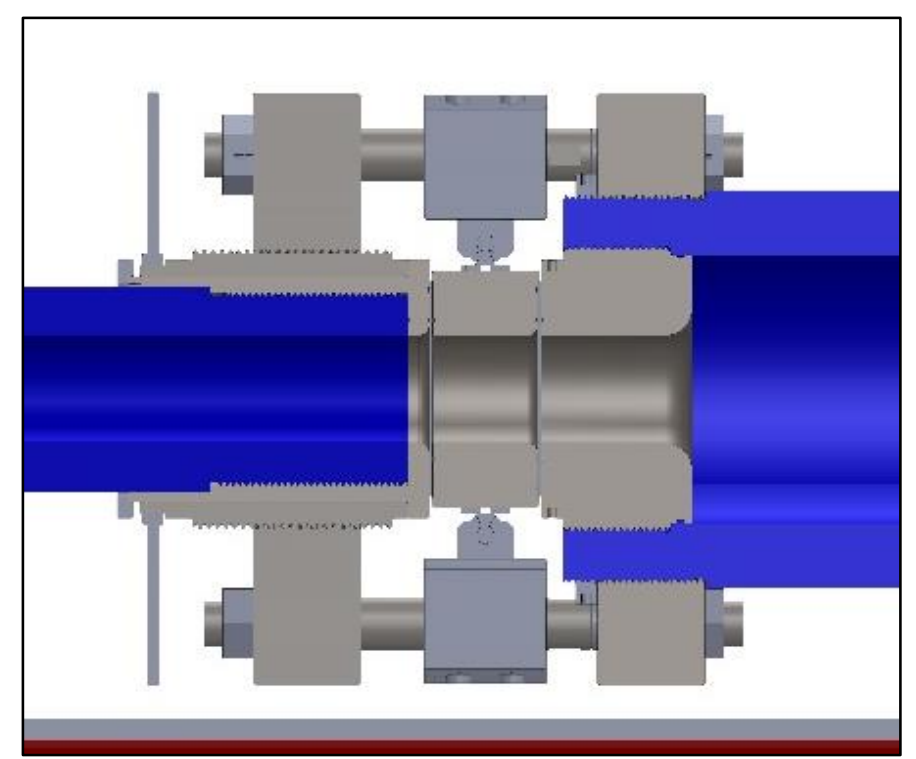

Figure 5: CAD section view of the CDST double diaphragm station arrangement

\section{Test Section Design}

The end of the shock tube has a separate $400 \mathrm{~mm}$ long optically accessible section containing the fuel injection equipment. This also has a bore of $100 \mathrm{~mm}$ and a maximum wall thickness of $67 \mathrm{~mm}$. Three windows were provided in the test section: two opposing windows to provide through-access for techniques such as schlieren imaging, diffused backlit imaging, and laser techniques such as laserinduced grating spectroscopy (LIGS) $[25,26]$; and a window with a viewing angle perpendicular to this to allow the introduction of illumination for techniques such as Mie scattering imaging or planar laser-induced fluorescence (PLIF). The test section also houses three pressure transducer ports for accurate measurement of pressure and timing of the incident and reflected shocks (from which gas temperature can be inferred). Figure 6 shows the test section in a cutaway visualization, with the key features labelled. The test section was manufactured using the same hubs as the rest of the facility, allowing the test section or end cap to be removed from the facility to allow window cleaning or alteration of the fuel injection system. This also allows the test section to be placed anywhere in the shock tube, not necessarily at the end.

The window size was selected to provide suitable optical access to the single-hole spray on the tube centreline, when operated at a range of conditions relevant to compression ignition combustion. At the inner face of the window, which is tangential to the bore of the tube, the window size is $70 \mathrm{~mm}$ in the spray-oriented axial direction and $30 \mathrm{~mm}$ in the spray-oriented radial direction. With the injector situated in the nominal position, the nozzle tip will be just visible at one side of the window and the spray near field region and main areas of the spray far field region can be simultaneously imaged and investigated. The dimensions shown in Table 2 show that much of the spray under Spray A conditions can be viewed utilizing these windows, with the injector in this position. The window length was set to a compromise value of $70 \mathrm{~mm}$ : whilst a longer optically accessibly region would be useful, this increases the stress concentrations at the corners of the window, due to the pressure loading on the test section. When access is required to spray regions

Page 6 of 9 at a distance greater than $70 \mathrm{~mm}$ from the spray nozzle, the shock tube end wall can be recessed from the window, or the test section may be reversed to place the window further from the end wall. The window design is shown in the section view presented in Figure 6, where the windows are shown fixed into their steel housing, which can be removed from the test section. The housing allowed the cavity in the body of the test section to be machined with rounded internal corners, to reduce the stress concentration here, whereas the windows were designed with sharp not rounded edges, due to manufacturing limitations. The fused silica windows are $48 \mathrm{~mm}$ thick, from Crystran, and were fixed into their housings using an epoxy encapsulant (Loctite Stycast 2850FT). A gasket sheet made up of compressed fibre with nitrile rubber binder, with anti-stick coating, sits between the windows and a holding down plate, ensuring that the push-out load on the windows is taken by the holding down plate and not transferred into the adhesive.

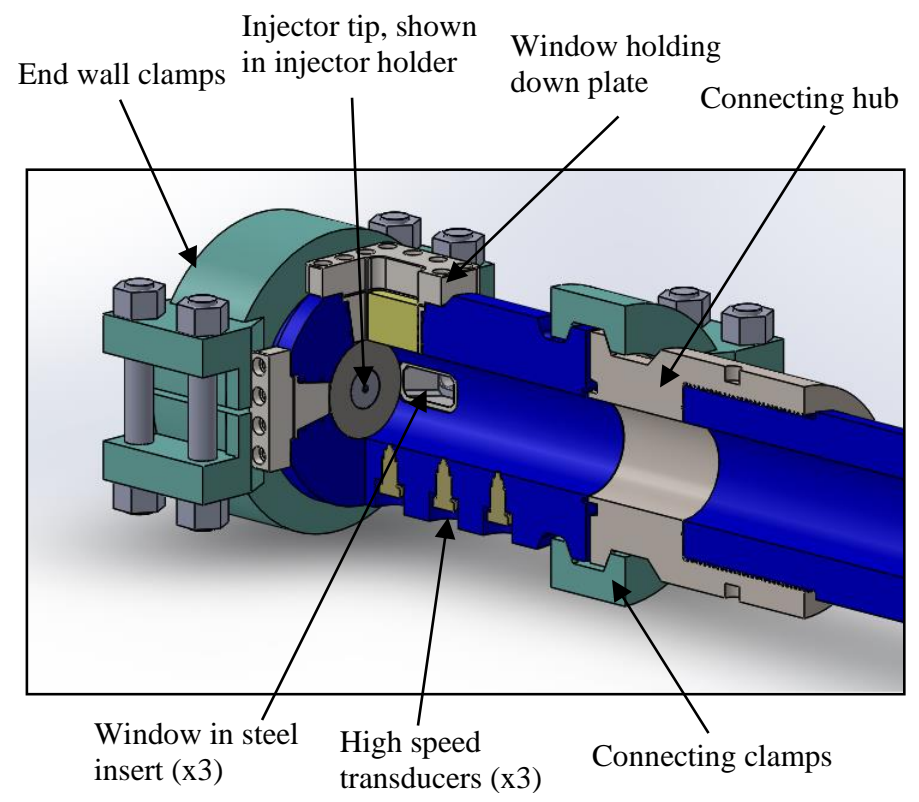

Figure 6: Cut away CAD view of the CDST test section, showing the mounted diesel injector in the centre of the shock tube end wall, high speed transducer locations and the extent of the optical access

\section{Fuel Injection System}

The end cap of the CDST has been machined to accommodate a diesel injector, specifically an ECN Spray A injector, although this can be adapted so that other injectors can be installed and investigated. In order to promote repeatability within ECN facilities, the injection system in Oxford CDST is designed to meet all standard Spray A requirements [9]. Fuel is first pressurized using an air driven fuel pump with a maximum capacity of 2200 bar (Maximator M189 VLE), requiring air at 10 bar. An ECN-specified common rail is installed to ensure minimum fuel pressure drop in the fuel supply during injection. The linking pipe between the injector and the common rail is set to be $24 \mathrm{~cm}$. The injector is obtained from the IFP first ECN pool with a nozzle part number of 102.04. Detailed injector characteristics can be found in a previous IFP study [27]. One of the fuel injection requirements for Spray A is to have fuel injected at a designated temperature of $363 \mathrm{~K}$ defined at the sac volume upstream of nozzle orifice. Studies have shown that the variation of fuel temperature at injection can change the spray penetration and vapour characteristics [9]. Although it is desirable to directly measure the injected fuel temperature at the orifice exit, the actual implementation 
is relatively challenging in such a facility. A more reasonable approach proposed by Pickett et al. [9] is to control the entire injector nozzle temperature. The fuel temperature regularization in the Oxford CDST is achieved through two compact high performance KIT Electroheat tubular cartridge heaters: the first heater (400 W, RPM series) is wrapped around the injector body to preheat the fuel; second heater ( $95 \mathrm{~W}$, RPI series) is fitted around the injector nozzle to compensate the heat losses to the shock tube chamber. Both heaters are equipped with a mineral insulated type $\mathrm{K}$ thermocouple to monitor the injector temperature, allowing closed loop feedback control. Injection is driven and triggered via a National Instruments Direct Injection Driver System (NI DIDS 2103), allowing userdefined current pulses to be delivered to the injector in order to reproduce a given injector flow rate profile, including multiple injections.

\section{Gas delivery systems}

For operation in air-driven, area change mode, high pressure dried compressed air is supplied by a 350 bar Gardner Denver 5437.1.IA compressor via a Donaldson Ultrafilter HLP-MSD high pressure dryer, regulated down to 150 bar for the CDST facility. The filling and firing operation for the CDST is controlled by a manually operated control panel at one end of the facility. The driven tubes are first evacuated to less than $133 \mathrm{~Pa}$, using an Edwards NXDS 20i dry scroll pump, with peak pumping speed of $22 \mathrm{~m}^{3} / \mathrm{h}$. Then, the driven tubes are filled to the desired $p_{1}$ pressure, up to a maximum of 10 bar. The driver and diaphragm block are filled next, from a vented state. The CDST is permanently connected to the compressed air supply, allowing for rapid, manual filling of the driver using a needle valve until the desired $p_{4}$ pressure is reached. During this operation a high pressure regulator (CONCOA 492 series) is continually adjusted to deliver pressurized air to the diaphragm block, ensuring that this intermediate pressure remains close to mid-way between the driven tube pressure and current driver pressure. The gas pressures are monitored via GEMS Sensors 3100 series and 3300 series pressure transducers, which were calibrated in-house. When the shock tube is to be fired, two high pressure solenoid valves) are activated. The first is a normally-open valve, which closes to isolate the diaphragm block from the feeding pipework; the second is a normally-closed valve, which vents the diaphragm block gas to atmosphere. This two valve system prevents accidental triggering of the experiment, and reduces the volume to be vented, which is $<1 \%$ than the driver volume, to allow for a clean diaphragm bursting event.

\section{Instrumentation and Control}

The tubes and test section are equipped with pressure transducers to record the shocks travelling down the tube and measure the pressure in the reflected shock region, from which the bulk temperature can be inferred. These transducers are high frequency PCB 113 series ICP sensors, and six are used along the length of the tube, with three in the test section for accurate measurement of pressure and shock speed (and hence temperature estimation). In the test section, the transducers have an ablative coating to improve thermal resistance from the high temperature reflected shock region, since temperature transients can generate additional unwanted signals [28]. There are three of these transducers in the test section, spaced $75 \mathrm{~mm}$ apart, with the final transducer at a nominal distance of $33 \mathrm{~mm}$ from the shock tube end wall. All of the PCB transducers have been mounted in a specially designed holder, which allows for close control over flush-mounting of the sensors with the bore of the tube. The sensors are signal conditioned using PCB Model 482C05 units, before data acquisition.

Page 7 of 9
Accurate driver and driven section pressure measurements are taken from Kulite XTL-190 pressure transducers, which are mounted into wall of the driver and shock tube. The Kulite transducers are provided power by a Fylde FE-379-TA modular amplifier, which also amplifies and conditions the signal before data acquisition.

Experimental control and data acquisition is performed using a dedicated National Instruments NI PXI system. This consists of a NI PXIe-8135 controller, operating Windows 7, with a NI PXIe-6368, X Series Multifunction DAQ module, capable of $2 \mathrm{MS} / \mathrm{s} / \mathrm{channel}$. With the six high speed sensors in operation, pressure data can be sampled at a resolution of $3 \mu \mathrm{s}$, to capture the transit of incident and reflected shocks. The experiment is controlled via a LabVIEW virtual instrument, previously used for the T4 shock tunnel [29], from where triggering signals may be sent to high speed cameras, illumination systems and to the DIDS to trigger fuel injection. Typically, the entire experiment is triggered when a selected pressure transducer records a pressure rise, indicating that a shock has passed it.

\section{Preliminary Results}

To demonstrate the capability of the Oxford CDST, some preliminary pressure history data and high speed fuel spray images are shown here. This experiment was captured using the area change driver, using 15 bar air as the driver gas and 2 bar nitrogen as the test gas. Double diaphragm operation was employed to set up and trigger the experiment. Shown in Figure 7 is the pressure history from the PCB transducer closest to the end wall, $33 \mathrm{~mm}$ upstream of the end wall. This shows a reflected shock pressure $p_{5}$ of 11.2 bar. The incident and reflected shock speeds were calculated by observing the pressure rise at different transducer locations. From this the calculated gas temperature $T_{5}$ in the test section $496 \mathrm{~K}$. At this condition, over $5 \mathrm{~ms}$ of test time is achievable.

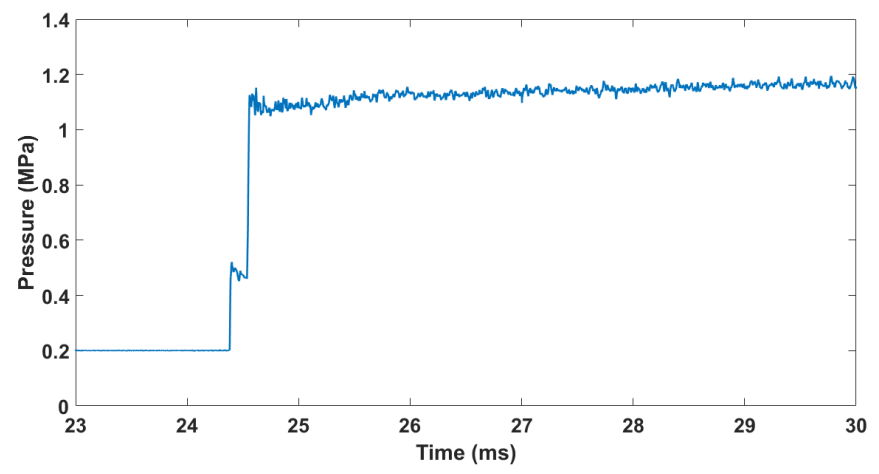

Figure 7: Pressure trace from PCB transducer located $33 \mathrm{~mm}$ from CDST end wall during preliminary run

The Spray A diesel injector described earlier in the paper was installed in the shock tube end wall, and was at room temperature during the experiment. The DIDS system triggered the fuel injector at a time of $27 \mathrm{~ms}$, with reference to Figure 7. Ordinary B0 diesel fuel was utilized, with an injection pressure of 1500 bar and an energizing time of $1 \mathrm{~ms}$. Visible fuel injection lasted around $2 \mathrm{~ms}$. In Figure 8, sample spray images from this event are shown, which were captured using diffuse backlit imaging at 18000 frames per second. 


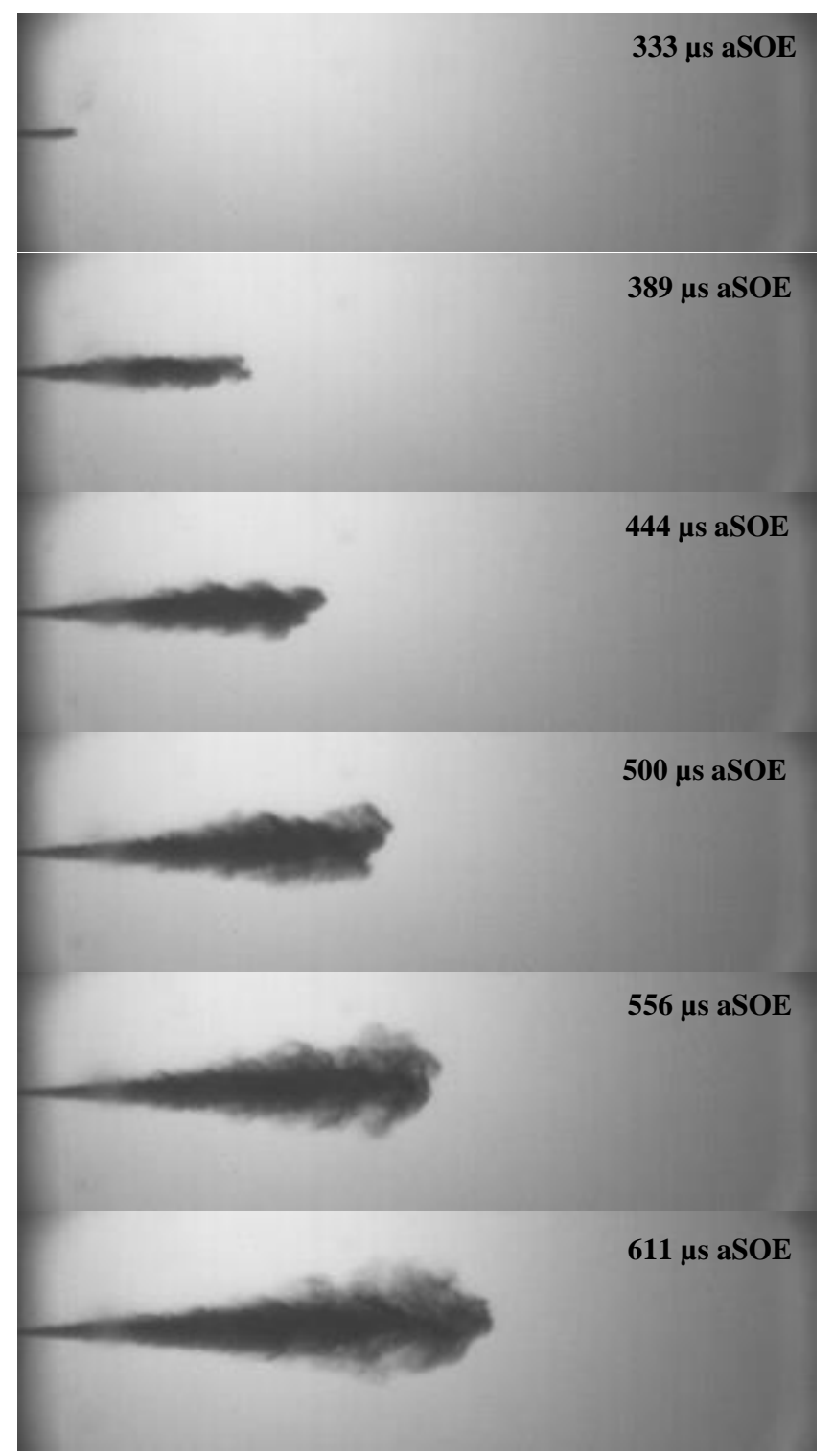

Figure 8: Sample spray images from the CDST run that generated the test section pressure trace shown in Figure 7. Diffused backlit imaging is used, and aSOE stands for time after start of energizing. The length of the image is approximately $66 \mathrm{~mm}$ on the shock tube centreline

\section{Summary}

This paper has introduced the Cold Driven Shock Tube at the University of Oxford: a newly built experimental facility specifically designed for the investigation of high pressure, high temperature fuel spray and chemical kinetics research. The selection of a reflected shock tube and the choice for the CDST of a cold driver is set in the context of other types of pressurized, high temperature vessel, and other existing shock tube facilities. This shock tube is projected to provide well-defined, repeatable boundary conditions for these experiments, with the current configuration set up for the ECN Spray A experiment. The CDST will allow experimental work at pressures up to 150 bar, exceeding many other available facilities. The high operating pressures have allowed a maximum optical window size of $70 \mathrm{~mm} \times 30 \mathrm{~mm}$, which will give suitable optical access to single-hole fuel sprays at conditions close to ECN Spray A. Page 8 of 9
The use of cold compressed air provides an economical method to generate experimental conditions at and around the Spray A condition. This obviates the need for heated gas or the use of more expensive compressed gases such as helium, argon, methane or hydrogen. This reduced operating cost in comparison to tailored shock tube operation results in a reduced steady condition test time. The speed and ease of operation, and reduced operating costs, make the CDST a useful tool to study these demanding experimental conditions.

The selection of the size and length of the CDST was informed by the dimensions of the types of sprays to be investigated and the desired test duration at the experimental conditions of interest. Aspects of the design of the CDST have been presented, including the optically accessible test section, the double diaphragm station for experimental triggering, the fuel delivery system for injection studies and the facility instrumentation. Finally, sample high speed diesel spray images and corresponding test section pressure history have been presented, to demonstrate the available optical access in the test section, the fuel injection system, and instrumentation and data acquisition.

\section{References}

1. Thermal Propulsion Systems Roadmap, Automotive Council UK, 2017.

2. Advanced Combustion and Emission Control Technical Team Roadmap, U.S. Drive, 2013.

3. Aransiola, E. F., Ojumu, T. V., Oyekola, O. O., Madzimbamuto, T. F et al., (2014). A review of current technology for biodiesel production: State of the art. Biomass and Bioenergy, 61, 276297.

5. Crua, C., Manin, J., \& Pickett, L. M. (2017). On the transcritical mixing of fuels at diesel engine conditions. Fuel, 208, 535-548. http://doi.org/10.1016/j.biombioe.2013.11.014.

6. Pickett, L. M., Kook, S., \& Williams, T. C. (2009). Visualization of Diesel Spray Penetration, Cool-Flame, Ignition, High-Temperature Combustion, and Soot Formation Using High-Speed Imaging. SAE International Journal of Engines, 2(1), 2009-01-0658. http://doi.org/10.4271/2009-01-0658

7. Wu, N., Bushe, W. K., \& Davy, M. H. (2010). On the experimental validation of combustion simulations in turbulent non-premixed jets. Combustion Theory and Modelling, 14(6), 855-874. http://doi.org/10.1080/13647830.2010.517274.

8. Stotz, I., Lamanna, G., Hettrich, H., Weigand, B., \& Steelant, J. (2008). Design of a double diaphragm shock tube for fluid disintegration studies. Review of Scientific Instruments, 79(12). https://doi.org/10.1063/1.3058609.

9. Pickett, L., Genzale, C., Bruneaux, G., Malbec, L. et al., "Comparison of Diesel Spray Combustion in Different HighTemperature, High-Pressure Facilities," SAE Int. J. Engines 3(2):156-181, 2010, https://doi.org/10.4271/2010-01-2106.

10. Verhoeven, D., Vanhemelryck, J.-L. and Baritaud, T., "Macroscopic and Ignition Characteristics of High-Pressure Sprays of Single-Component Fuels", SAE Technical Paper 981069, 1998.

11. Aerothermochemistry and Combustion Systems Laboratory, ETH Zürich, http://www.lav.ethz.ch/research/opticaldiagnostics-group.html, accessed 02/01/2018.

12. Payri, R., García-Oliver, J. M., Manin, J. and Bardi, M., "Fuel temperature influence on Diesel sprays in reacting conditions", ILASS-Americas 23rd Annual Conference on Liquid Atomization and Spray Systems, Ventura, CA, May 2011. 
13. Aye, M., Beeckmann, J., Vanegas, A., Peters, N. et al., "Experimental Investigation of Diesel and Surrogate Fuels: Spray and Ignition Behavior," SAE Technical Paper 2011-011921, 2011, https://doi.org/10.4271/2011-01-1921.

14. Combustion Chemistry Centre, http://c3.nuigalway.ie/facilities.html, accessed 02/01/2018.

15. Crua, C., "Combustion Processes in a Diesel Engine", $\mathrm{PhD}$ Thesis, University of Brighton, 2002.

16. Wu, N., "Autoignition And Emission Characteristicsof Gaseous Fuel Direct-Injectioncompression-Ignition Combustion", $\mathrm{PhD}$ Thesis, University of British Columbia, 2007.

17. Darcy, D., Mehl, M., Simmie, J.M., Würmel, J. et al., “An experimental and modeling study of the shock tube ignition of a mixture of n-heptane and n-propylbenzene as a surrogate for a large alkyl benzene", Proceedings of the Combustion Institute, 34(1), 2013, 411-418, https://doi.org/10.1016/j.proci.2012.06.131.

18. Davidson, D. F., Haylett, D. R., \& Hanson, R. K. (2008). Development of an aerosol shock tube for kinetic studies of lowvapor-pressure fuels. Combustion and Flame, 155(1-2), 108117. http://doi.org/10.1016/i.combustflame.2008.01.006

19. Wang, W., Gowdagiri, S., \& Oehlschlaeger, M. A. (2014). The high-temperature autoignition of biodiesels and biodiesel components. Combustion and Flame, 161(12), 3014-3021. http://doi.org/10.1016/j.combustflame.2014.06.009

20. Tekawade, A., Xie, T., \& Oehlschlaeger, M. A. (2017). Comparative Study of the Ignition of 1-Decene, trans-5-Decene, and n-Decane: Constant-Volume Spray and Shock-Tube Experiments. Energy and Fuels, 31(6), 6493-6500. http://doi.org/10.1021/acs.energyfuels.7b00430

21. Engine Combustion Network (ECN) Data Search Page, https://ecn.sandia.gov/ecn-data-search/, October 2017.

22. Jacobs, P. A., "Shock Tube Modelling with L1d.", Research Report 13/98, Department of Mechanical Engineering, The University of Queensland, 1998.

23. L1d3 - Compressible Flow CFD 3 Documentation, http://cfcfd.mechmining.uq.edu.au/11d3.html, accessed 01/10/2017.

24. Schemperg, K. and Mundt, C., "Study of Numerical Simulations for Optimized Operation of the Free Piston Shock Tunnel
HELM". 15th AIAA International Space Planes and Hypersonic Systems and Technologies Conference, AIAA 2008-2653, https://doi.org/10.2514/6.2008-2653, 2008.

25. Williams, B., Edwards, M., Stone, R., Williams, J., et al., "High precision in-cylinder gas thermometry using Laser Induced Gratings: Quantitative measurement of evaporative cooling with gasoline/alcohol blends in a GDI optical engine", Comb. Flame, 161(1):270-279, 2014, https://doi.org/10.1016/j.combustflame.2013.07.018.

26. Förster, F. J., Crua, C., Davy, M., Ewart, P., Exp Fluids (2017) 58: 87. https://doi.org/10.1007/s00348-017-2370-6

27. Malbec, L.-M., Esquiza, J., Bruneaux, G. and Meijer, M., "Characterization of a set of ECN Spray A injectors: Nozzle to nozzle variations and effect on spray characteristics". SAE Int. J. Engines, 6:1642-1660, 092013

28. Model 113B22 ICP® Pressure Sensor Installation and Operating Manual, PCB Piezotronics, 2013.

29. Ridings, A. N., (2012). "UQ's T4 Shock Tunnel Data Acquisition System". In: National Instruments Technical Symposium 2012. Brisbane, Queensland, Australia.

\section{Contact Information}

Joseph Camm, joseph.camm@eng.ox.ac.uk

\section{Acknowledgments}

This work was funded by the EPSRC under the grant: "Ultra Efficient Engines and Fuels", Grant no. EP/M009424/1. The authors would also like to acknowledge the assistance provided in building and commissioning the CDST by: Bill Godfrey, Hal Surtell, Jason McCluskey, Aston Tyrrell, Phil Bower, Gerald Walker, Duncan Blake, Paul Cox and Louis Nicholson. 